\title{
Trypanosoma cruzi discrete typing units in patients of Chagas disease and Triatoma infestans after insecticide spraying in Chile Sylvia Ortiz ${ }^{1}$, Rodrigo Villarroel ${ }^{2}$, Beatriz Cancino ${ }^{3}$, Maria Inés Jercic ${ }^{4}$, Aldo Solari ${ }^{5}$ \\ ${ }^{1,5}$ Programa de Biologia Celular y Molecular. ICBM. Facultad de Medicina. Universidad de Chile \\ ${ }^{2,3,4}$ Unidad de Parasitología, Instituto de Salud Pública de Chile
}

Address correspondence to Aldo Solari, Programa de Biología Celular y Molecular, Facultad de Medicina, Universidad de Chile, Casilla 70086, Santiago 7, Chile.

\begin{abstract}
In this study, we evaluate mixed discrete typing units (DTUs) of Trypanosoma cruzi present in 69 patients of Chagas disease and 92 Triatoma infestans collected under the entomological surveillance program after more than 20 years of intervention with insecticide spraying in Chile. Our aim is to identify T. cruzi DTUs still circulating in T. infestans and chronic patients to evaluate their impact on the environmental health in endemic areas of the country. Blood DNA or triatomine DNA was used as DNA template for PCR assays. For genotyping, different T. cruzi stocks were used to generate the DNA probes to determine four parasite DTUs or mixtures infecting each patient or vector by means of hybridization assays. We found different frequencies of T. cruzi DTUs in patients and in T. infestans. Tc I was the most frequent found in T. infestans, but was less frequent in humans. In contrast, in humans Tc $V$ was most frequent but was less frequent in $T$. infestans. In conclusion, there were significant differences between the T. cruzi DTUs circulating in patients and vectors. We discussed these results in the context of what has being reported in Chile before the vector control, in neighboring countries, and the selection pressures existing for T. cruzi populations within the invertebrate and vertebrate hosts.
\end{abstract}

Keywords-Chagas disease in Chile, Trypanosoma cruzi DTUs, Triatoma infestans, kinetoplast minicircles.

\section{INTRODUCTION}

Chagas disease is widespread in Chile, distributed in rural and peri-urban areas in the seven endemic regions of the country. Human Chagas disease presents two distinct phases: the acute phase, which appears just after infection, and the chronic phase, which may last several years. After a long asymptomatic phase, around $30 \%$ of infected individuals develop chronic disease with severe damage to the heart and digestive system [Arribada et al., 1986]. Microscopic examinations of fresh or stained blood smears, xenodiagnosis and hemoculture are methods used for detected T. cruzi during the acute phase. In contrast, the detection is by circulating antibodies during the chronic phase. Triatoma infestans (Hemiptera, Reduviidae), a strictly hematophagous and almost exclusively domestic species, is the main vector of Trypanosoma cruzi, the causative agent of Chagas disease, in the southern cone of South America [Lent and Wygodzinsky 1979, Zeledón 1983]. Domestic animals are excellent hosts for these insects. The peri-domestic area around human houses in rural villages is very important, because it usually includes heavily infested goat corrals, chicken coops, rabbit cages and storerooms, which in many cases are just a few meters from the house [Gürtler 1993, 1997, Cecere et al., 1997, López et al., 1999, OMS 2002, Catalá et al., 2004]. In Chile, it attempted disruption of the domestic cycle of transmission of T. cruzi by means such as health education, improvement of housing and vector elimination by applying insecticides to human dwellings. Along northern areas where the domiciliary vectors were present systematic insecticide spraying with the support of health authorities it was applied during the last 20 years. Goat corrals are the main refuge for the peri-domestic populations of $T$. infestans and one of the ecotopes in which pyrethroid insecticides show low efficiency against these insects [Cecere et al., 1997, Gürtler et al., 2004]. Chicken coops are also very frequent and maintain abundant vector populations. Infested peri-domestic places could act as sources of house re-infestation after insecticide application [Gürtler et al., 2004], because of the movement of insects between habitats [Schofield 1985]. Although T. cruzi infection in peri-domestic T. infestans is not as frequent as in intra-domestic insects, the peri-domestic structures may be important sources of vector specimens. Chagas disease represents a major public health 
problem in America, with an estimated 16-18 million people infected by Trypanosoma cruzi [Moncayo, 2003]. In the most endemic areas of this disease of Chile, the Norte Grande and Norte Chico, there are an estimated 150,000 infected people, even though the only domiciliary vector Triatoma infestans has been controlled since 2000 [Lorca et al., 2001]. However, there are still geographic areas with infection rates of $0.55 \%$ and very low T. infestans infestation rates [Jercic et al., 2011]. The clinical symptoms of chagasic patients are cardiological or/and digestive dysfunction in about 1/3 of the chronic infected subjects. In Chile most cases are reported as diseases in other organs (50.6\%), followed by cardiological dysfunction (44.6\%) and digestive dysfunction (4.7\%) [Moncayo, 2003]. The etiologic agent T. cruzi is composed of six DTUs (TcI-TcVI). Efforts to find the association between the infective T. cruzi DTUs with clinical manifestations have been made all over Latin America [ Zingales et al., 2012]. In Chile there are reports indicating that TcI, TcII, TcV and TcVI, studied with different molecular markers, are prevalent (including mixed infection) [Sanchez et al., 1993; Rozas et al., 2005; Coronado et al., 2006; Arenas et al., 2012]. T. cruzi belongs to the order Kinetoplastida, a group of parasitic organisms with an organelle called a kinetoplast, which contains DNA in concatenated minicircles and maxicircles. The minicircles are very abundant (10,00020,000 copies/cell), and therefore represent a perfect DNA target for diagnosis by means of PCR-DNA amplification. These amplicons are also useful for genotyping the T. cruzi DTUs, since minicircles are composed of different classes which may be used to characterize T. cruzi lineages by DNA-DNA hybridization methods [Veas et al., 1991; Brenière et al., 1998; Torres et al., 2004]. Each minicircle (1400bp) contains four constant regions intercalated with four hypervariable regions, which vary among the different minicircle classes present in each T. cruzi DTU [Arenas et al., 2012]. The medical entomology laboratory of the Institute of Public Health, analyzed samples of $T$. infestans. The Regional Ministerial Secretariats (SEREMIS) of Atacama, Valparaíso and Metropolitana provided triatomines captured in the period 2005-2010 of which $28.5 \%$ were infected. Parallel to the studies with the vector, there were a series of studies of serological screenings in children under 5 years old and their families between the regions of Arica and Parinacota and O'Higgins. Five thousand one hundred eleven screenings were preformed, with 28 positive cases $(0.55 \%)$, a value close to the $0.7 \%$ prevalence obtained by the National Health Survey (NHS) 2009-2010 (Jercic et al., 2011). Our study, framed by the recommendations of the Panamerican Health Organization Initiative of Countries of the Southern Cone, sought to evaluate the effectiveness of the programs of vector elimination carried out in Chile [OPS, 2002]. The Chilean Health Ministry and the Public Health Institute (PHI) confirmed each chagasic patient by means of serological methods, as well as the infected or non-infected status of the triatomines, by means of PCR diagnosis. This epidemiological information is relevant to direct the necessary efforts to spray human dwellings with insecticides and try to eradicate $T$. infestans. In this study, we evaluate the $T$. cruzi DTUs present in random representative samples of these patients and $T$. infestans collected in all endemic areas of the country under the entomological surveillance program of the Ministry of Health. Our aim is to identify $T$. cruzi DTUs currently circulating in $T$. infestans and non-treated chronic adult patients to analyze the $T$. cruzi DTUs circulating in the survivors in both hosts in an extensive area of Chile. We pretend to analyze the interactions between $T$. cruzi parasites and its hosts in order to evaluate their impact on the environmental health. To accomplish this goal we used a direct method to genotype $T$. cruzi, to avoid selection of $T$. cruzi clones from mixed infections during the parasite isolation and amplification processes.

\section{MATERIALS AND MethodS}

\subsection{Patients}

Blood samples of 69 chagasic patients were obtained from regions XV (Arica-Parinacota), I (Tarapacá), II (Antofagasta), III (Atacama), IV (Coquimbo), V (Valparaíso), RM (Región Metropolitana) and VI (O’Higgins). Fig.1 shows a map of Chile describing the geographic regions. The whole area remained untreated with insecticides, except in the cases of re-infestation, during the 20 years before the present study. To ascertain chagasic patients we applied two of the three serological methods (ELISA, indirect inmunofluorescence and/or Western blot) at PHI. An infected case gives positive result with two methods. 


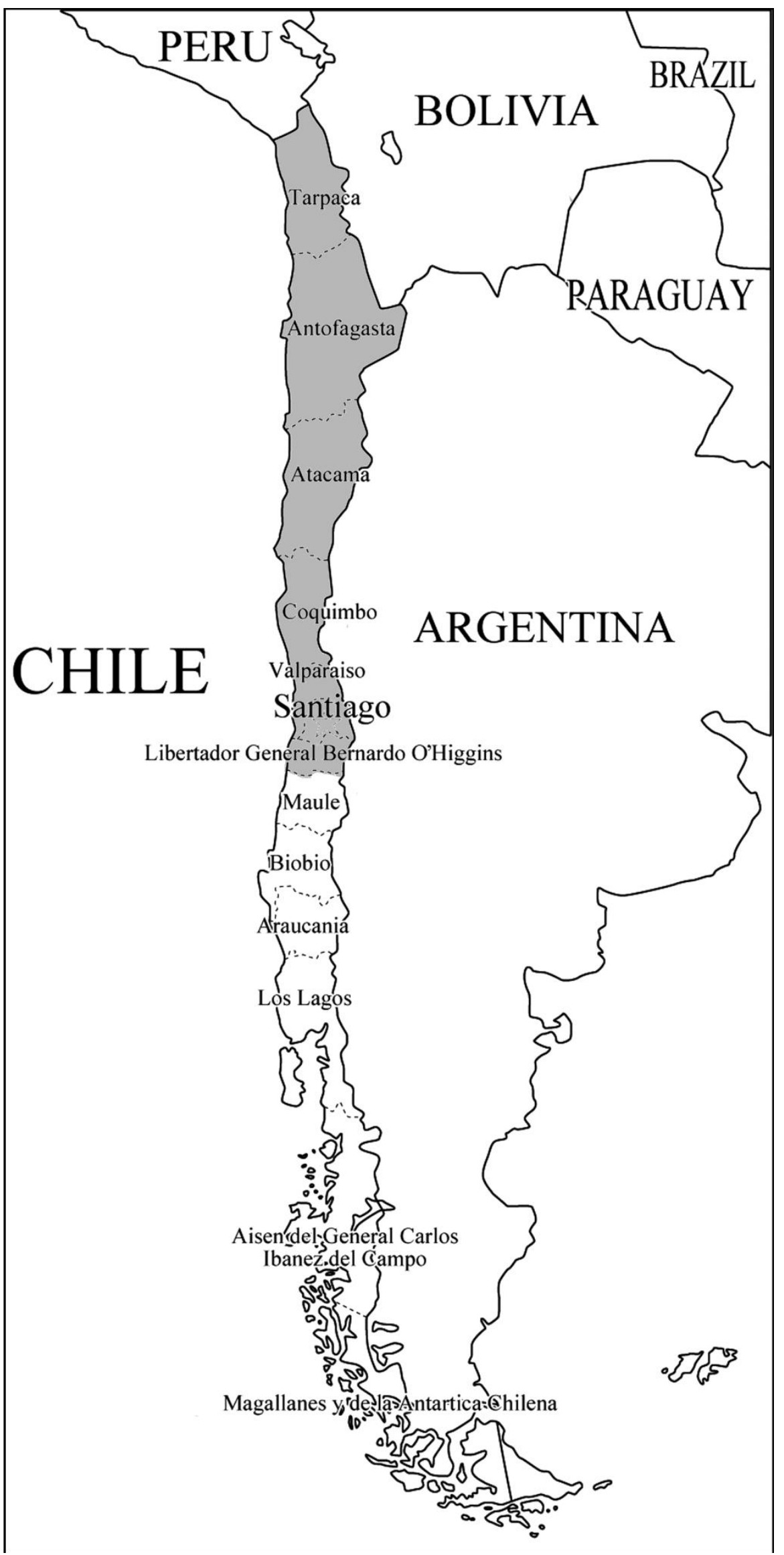

FIGURE 1. MAP OF CHILE (GRAY AREAS) INDICATING THE REGIONS FROM WHICH THE SAMPLES CAME. 


\subsection{Triatomines}

Intra-domiciliary Triatomines ( $\mathrm{n}=92$ ) were from regions III (Atacama), IV (Coquimbo), V (Valparaíso) and RM (Región Metropolitana). Triatomines from the Norte Grande and the VI region were not available due to absence of notifications from local health authorities. Local personnel of the surveillance program of the Ministry of Health transported the dead insects to the PHI for species identification and determination of infection status with $T$. cruzi by PCR assays as described [Jercic et al., 2011]. Hindgut of each triatomine was used to DNA extraction according to the manufacturer's instructions (EZNA Blood DNA Mini Kit OMEGA biotek, Nercross, GA) and used as DNA template for PCR.

\subsection{Blood samples}

The samples of peripheral blood of the patients were preserved in Guanidine-EDTA as described [Wincker et al., 1994] and boiled for 15 minutes at $98{ }^{\circ} \mathrm{C}$ before extraction and purification of DNA using the Favorgen kit according to the manufacturer's instructions, and maintained at $-20^{\circ} \mathrm{C}$ until use (Biotech, Corp., Selangor, Malaysia).

\section{$2.4 \quad$ Minicircle PCR assay}

A blood DNA or triatomine DNA sample $(5 \mu \mathrm{L})$ was used as DNA template for PCR. The reactions were performed in triplicate with oligonucleotides 121 and 122, which anneal to the four conserved regions present in minicircles of $T$. cruzi [Wincker et al., 1994], including a positive and negative control in each test. The 330-base pair PCR product was separated by electrophoresis in a $2 \%$ agarose gel and visualized by staining with ethidium bromide.

\subsection{DNA blot assay}

T. cruzi DTU genotyping in the patients and vectors was performed by DNA blot of minicircle amplicons, as described previously [Veas et al., 1991]. Briefly, $10 \mu \mathrm{l}$ of each PCR product was subjected to electrophoresis, transferred onto a Hybond N+ nylon membrane (Amersham, Little Chalfont, United Kingdom) and cross-linked with ultraviolet light to fix the DNA. The membranes were pre-hybridized for at least 2 hours at $55^{\circ} \mathrm{C}$ and hybridized with different probes of T. cruzi minicircle $\mathrm{P}^{32}$-labeled DNA $\left(1 \times 10^{6} \mathrm{cpm} /\right.$ membrane $)$. Nylon membranes were then submitted to successive washing at different conditions of stringency [10]. For genotyping, different $T$. cruzi stocks were used to generate the DNA probes to determine the parasite DTUs or mixture infecting each patient or triatomine. Construction of specific probes sp104 c11 TcI, CBB c13 TcII, NR c13 TcV, and V195 cl1 TcVI was performed by amplification of the variable region of $T$. cruzi minicircles; primers for probe generation were CV1 (5'GATTGGGGTTGGAGTACTAT-3') and CV2 (5'TTGAACGGCCCTCCGAAAAC-3'), which produced a 270-bp fragment [Veas et al., 1991].The specificity of the probes was previously set in DNA blot experiments with $T$. cruzi clones genotyped by other methods [Arenas et al. 2012]. The DNA probes were labelled using the random primer method with $\left[\alpha^{32} \mathrm{P}\right]$ dATP and the hybridization profiles were analyzed. Finally, the membranes were scanned in a P-Imager (BioRad, USA) for 4-12 hrs. We used the chi-square test for comparing the T. cruzi DTUs circulating in both hosts and for comparing T. cruzi DTUs detected and no detected in both hosts.

\section{RESULTS}

We obtained different $T$. cruzi DTUs frequencies in patients and in T. infestans (Table 1). Tc I was the most frequent DTU in $T$. infestans but less frequent in humans. In contrast, $\mathrm{Tc} \mathrm{V}$ was the most frequent DTU found in humans and less frequent in $T$. infestans $\left(x^{2}=63.75\right.$; d.f. $\left.=1 ; \mathrm{p}=0.05\right)$. These two DTUs were the most prevalent; however, we also found two other $T$. cruzi DTUs (Tc II and occasionally Tc VI) which are circulating in T. infestans and humans in all the endemic areas of Chile, with no evident geographical distribution (Table I). We found T. cruzi DTUs alone or combined with other different DTUs, representing mixed infections. Fig.2 shows representative results of single and mixed infection of patients and Fig. 3 the same in T. infestans. We detected more mixed infections in humans than in T.infestans. As shown in the rate mixture of lineages/total studied, and the relative percentage of each. The average frequency of $\mathrm{TcV}$ detected in humans was very similar in the different geographic areas studied. Even though the space of this longitudinal study covered about $2000 \mathrm{kms}$ and included the Atacama Desert, which splits the country into two endemic areas, the Norte Grande and the Norte Chico. The principal endemic area is the semiarid Norte Chico, in the III, IV, and V political regions. Other T. cruzi DTUs different to Tc I, Tc II, TcV and Tc VI are circulating in both kinds of hosts in all endemic areas studied. We found these unknown $T$. cruzi DTUs more frequently in humans than in $T$. infestans $(43.4 \%$ vs. $11.9 \%)\left(x^{2}=11.48 ;\right.$ d.f. $\left.=1 ; \mathrm{p}=0.05\right)$. Frequency $(\%)$ of mixed infections with more than one T. cruzi DTUs, including those not determined, in patients exceeds that found in $T$. infestans (156.2 versus 120.5 respectively). 


\section{TABLA 1}

TRYPANOSOMA CRUZI DTUS (TcI, TcII, TcV, TcVI) IN CHILEAN PATIENTS AND IN TRIATOMA INFESTANS (T.I.)

\begin{tabular}{|c|c|c|c|c|c|c|c|c|c|c|c|c|}
\hline $\begin{array}{l}\text { Geographic } \\
\text { region } N>S\end{array}$ & $\begin{array}{c}\text { Patiens } \\
\text { TcI }\end{array}$ & TcII & $\mathrm{TcV}$ & TeVI & ND & M/TE & $\begin{array}{l}\text { T. } i . \\
\text { TeI }\end{array}$ & TcII & $\mathrm{TcV}$ & TeVI & ND & M/TE \\
\hline XV Arica & 4 & 3 & 2 & 0 & 6 & $3 / 10$ & $*$ & $*$ & $*$ & $*$ & & \\
\hline I Tarapacá & 3 & 5 & 6 & 0 & 1 & $3 / 10$ & $*$ & * & * & * & & \\
\hline II Antofagasta & 1 & 1 & 5 & 1 & 4 & $2 / 8$ & $*$ & $*$ & $*$ & $*$ & & \\
\hline III Atacama & 0 & 2 & 2 & 1 & 5 & $1 / 8$ & 21 & 2 & 5 & 0 & 7 & $4 / 24$ \\
\hline IV Coquimbo & 0 & 1 & 4 & 2 & 5 & $2 / 7$ & 12 & 4 & 0 & 0 & 1 & $0 / 17$ \\
\hline V Valparaíso & 1 & 2 & 7 & 4 & 2 & $4 / 9$ & 24 & 9 & 0 & 0 & 3 & $4 / 28$ \\
\hline R. Metropolitan & 3 & 3 & 5 & 1 & 4 & $3 / 9$ & 23 & 0 & 0 & 0 & 0 & $0 / 23$ \\
\hline VI O'Higgins & 2 & 3 & 4 & 0 & 3 & $2 / 8$ & $*$ & $*$ & $*$ & $*$ & & \\
\hline Total & 14 & 20 & 35 & 9 & 30 & $20 / 69$ & 80 & 15 & 5 & 0 & 11 & $8 / 92$ \\
\hline Frequency $(\%)$ & 20.2 & 28.9 & 50.7 & 13.0 & 43.4 & 28.9 & 86.9 & 16.3 & 5.4 & 0 & 11.9 & 8.6 \\
\hline
\end{tabular}

N>S: north to south ND: non determined * without samples M/TE: mixture of lineages/total studied

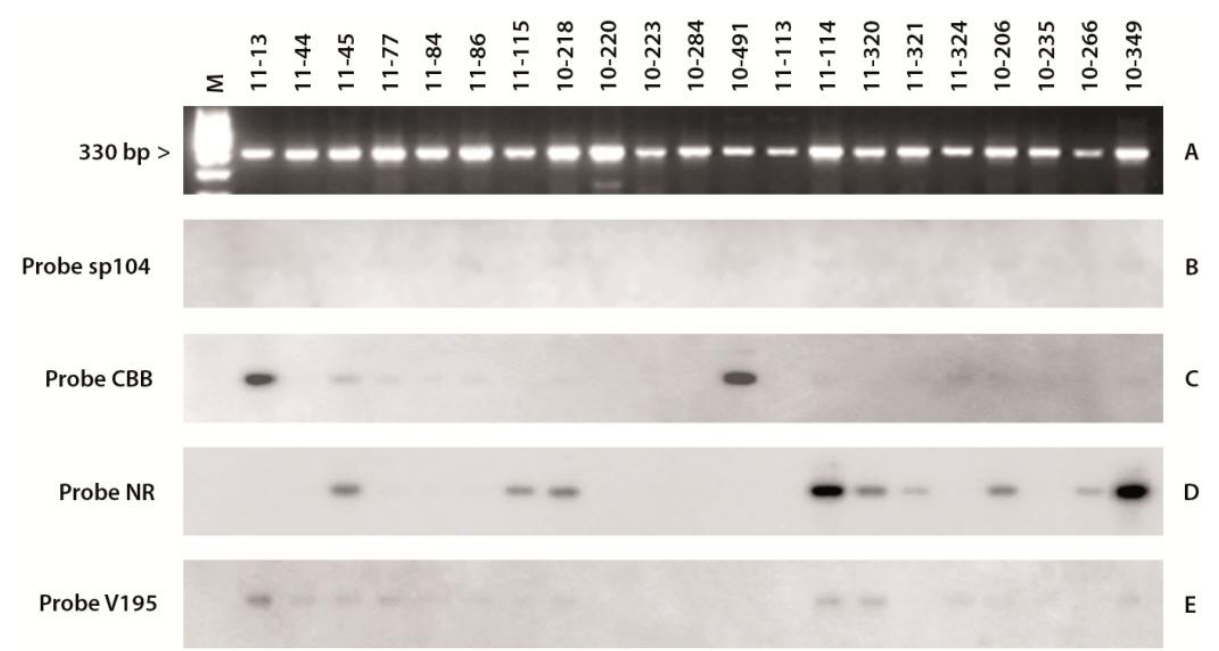

FIGURE 2. RESULTS WITH PATIENTS. TRYPANOSOMA CRUZI AMPLICONS STAINED WITH ETHIDIUM BROMIDE

(A). HYBRIDIZATION PROFILES OBTAINED WITH GENOTYPE SPECIFIC PROBES CORRESPONDING TO TCI (B),

TcII (C), TcV (D), and TcVI (E). THE 330 BASE PAIR (bp) PRODUCT REPRESENTS A POSITIVE ASSAY

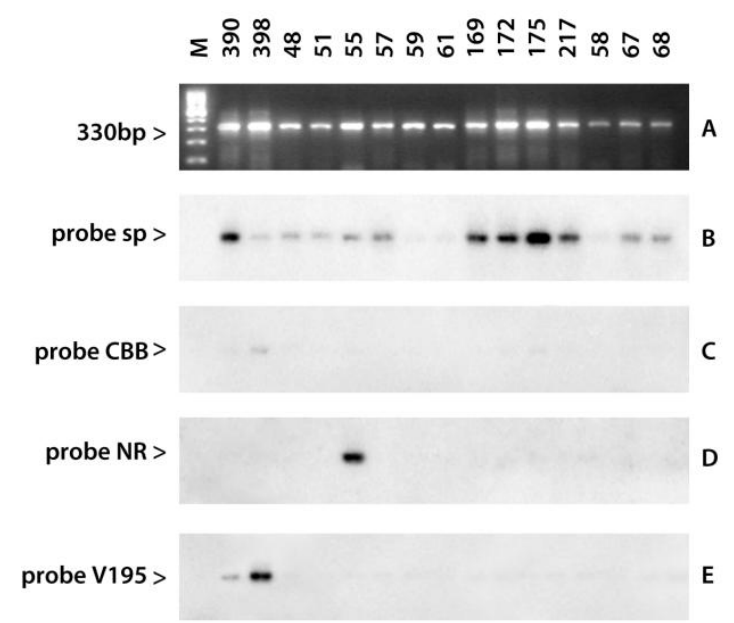

FigURE 3. RESULTS WITH TRIATOMA INFESTANS. TRYPANOSOMA CRUZI AMPLICONS STAINED WITH ETHIDIUM BROMIDE (A). HYBRIDIZATION PROFILES OBTAINED WITH GENOTYPE SPECIFIC PROBES CORRESPONDING TO TeI (B), TcII (C), TeV (D), and TcVI (E). THE 330 BASE PAIR (bp) PRODUCT REPRESENTS A POSITIVE ASSAY 


\section{DISCUSSION}

Previous epidemiological surveys of $T$. cruzi lineages isolated from patients and triatomines of the Norte Chico have been performed [Miles et al., 1984]. However, the studies in the Norte Grande involved small sample sizes [Arribada et al., 1986; González et al., 1995]. In the present study a large number of mixed infections in humans (TcV plus another DTU) were found in the less endemic arid areas of Norte Grande (XV, I and II regions), with levels of mixed infections similar to the most endemic ones (III, IV, and V regions). The T. cruzi DTUs composition in T. infestans (mainly TcI) also presented a very homogeneous distribution all over the studied area, as previously described [Bacigalupo et al., 2012]. Interestingly, unknown genotypes were not as frequent as in human patients. Probably these unknown genotypes are not well adapted to this invertebrate host or are eliminated in T.infestans under starvation, since the insects studied were dead. These unknown genotypes probably are variants of TcI and TcII for which there is great heterogeneity as determined by cytochrome b gene sequencing [Arenas et al. 2012]. There studies performed with T. cruzi stocks isolated in patients of Chile [Miles et al., 1984; Apt et al., 1987; González et al., 1995]; which select specific T. cruzi DTUs from a natural mixture as demonstrated [Deane et al., 1984; Miles and Cibulskis, 1986]. The frequency order of T. cruzi DTUs isolated from humans in the IV region was TcV, TcII, TcI [Miles et al., 1984; Apt et al., 1987]. However, a high prevalence of Tc I T. cruzi stocks was only detected in T. infestans of Tarapacá (I region) [Allen, 1984]. Other studies reported the presence of Tc I and only very few Tc V in $T$. infestans of southern Peru [Allen, 1984]. However, the most complete studies are from Bolivia, with surveys of T. cruzi stocks from T. infestans in diverse geographic areas close to the Chile border. Tibayrenc et al. 1986 reported TcI and only very few Tc V in the north (La Paz), TcI, TcV, TcVI and TcII in the south (Tupiza and Tarija), and TcI and TcV in eastern Bolivia (Santa Cruz). The T. cruzi DTUs composition in the west side of Argentina close to the Chilean border is also available. In the north area near the Andes the T. cruzi DTUs found in humans are TcV, but other DTUs such as TcI, TcII and TcVI also have been described [de Luca D'Oro et al., 1993; Macina et al., 1987; Diosque et al., 2003]. However, other surveys in northwest Argentina including domestic animals and T.infestans recorded mainly TcVI [Cardinal et al., 2008]. Results obtained with the same methods used here of T. cruzi DTUs in Argentinean patients confirmed the presence of TcV and TcVI alone or mixed [Diez et al., 2010]. In conclusion, the analysis of T. cruzi DTUs composition between patients and T. infestans in Chile found significant differences, even though the route of transmission to humans is through T. infestans than by vertical transmission or blood transfusion. $\mathrm{TcV}$ was most often found in patients infected several years ago, while the most often found currently in T. infestans is TcI A similar conclusion was reached in an area of Cochabamba, Bolivia. With the same direct genotyping method with no or little triatomine intervention; Tc I and TcV are prevalent in T. infestans and Tc $\mathrm{V}$ in humans, respectively [Brenière et al., 1998]. The results in Chile may account for the effectiveness of the method of flow interruption of $T$. cruzi DTUs between the vector and the human host, but this conclusion should be considerer with caution. The same differences were obtained in Bolivia without or very few insecticide applications. This difference suggests differential adaptation of the T. cruzi DTUs to different hosts. In Chile and from some areas of Bolivia the major DTUs Tc I and $\mathrm{TcV}$ alone or combined were prevalent; the former appears to be better adapted to the triatomine and the latter to the human host and distributed over a wide geographic area. These results also suggest that both $T$. cruzi DTUs are successfully circulating in nature, one more prevalent in the vertebrate and the other in the invertebrate host. Thus, both T. cruzi DTUs coexist due the alternation of parasites in the two kinds of hosts. This observation has pivotal importance, since a digenetic parasite such as $T$. cruzi will have more opportunities to amplify than in a monogenic one. Intrestingly Tc V seems to be more pathogenic compared with Tc I evaluated in a murine experimental model [Wallace et al., 2001].

\section{ACKNOWLEDGEMENTS}

This work was financial supported by FONDECYT - Chile 116-0080 to A. Solari.

\section{REFERENCES}

[1] Allen S. (1984). Isolation and isoenzyme characterization of Trypanosoma cruzi stocks from Chile and Peru. Master of Science. Thesis. University of London.

[2] Apt W, Aguilera X, Arribada A, Gomez L, Miles MA, Widmer G. (1987). Epidemiology of Chagas' disease in northern Chile: isozyme profiles of Trypanosoma cruzi from domestic and sylvatic transmission cycles and their association with cardiopathy. Am J Trop Med Hyg 37: 302-307.

[3] Arenas M, Campos R, Coronado X, Ortiz S, Solari A. (2012). Trypanosoma cruzi Genotypes of Insect Vectors and Patient with Chagas of Chile Studied by means Cytochrome b Gene Sequencing and Minicircle Hybridization, and Nuclear Gene Polymorphism. Vector Borne Zoonotic Dis. 12(3): 196-205.

[4] Arribada A, Apt W, Ugarte JM. (1986). Follow up survey of chagasic cardiopathy in Chile. PAHO Bull 20(3): 245-66. 
[5] Bacigalupo A, Segovia V, García A, Botto-Mahan C, Ortiz S, Solari A, Acuña-Retamar M, Torres-Pérez F, Cattan PE. (2012). Differential Pattern of Infection of Sylvatic Nymphs and Domiciliary Adults of Triatoma infestans with Trypanosoma cruzi Genotypes in Chile. Am J Trop Med Hyg 87(3): 473-480.

[6] Brenière SF,Bosseno MF, Telleria J, Bastrenta B, Yacsik N, Noireau F, Alcazar J L, Barnabé C, Tibayrenc M.(1998). Different behavior of two Trypanosoma cruzi major clones: transmission and circulation in young Bolivian patients. Exp Parasitol 89(3): 285295.

[7] Catalá SS, Crocco LB, Muñoz A, Morales G, Paulone I, Giraldez E, Candioti C, Ripol C (2004) Entomological aspects of Chagas' disease transmission in the domestic habitat, Argentina. Rev Saude Publica 38:216-222.

[8] Cardinal MV, Lauricella M A, Ceballos LA, Lanati L, Marcet P L, Levin MJ, Kitron U, Gürtler RE, Schijman AG.(2008). Molecular epidemiology of domestic and sylvatic Trypanosoma cruzi infection in rural northwestern Argentina.Int J Parasitol 38(13): 1533-43.

[9] Cecere MC, Gürtler RE, Canale D, Chuit R, Cohen JE. (1997) The role of the peridomiciliary area in the elimination of Triatoma infestans from rural Argentine communities. Pan American Journal of Public Health1:273-279.

[10] Coronado X, Zulantay I, Albrecht H, Rozas M, Apt W, Ortiz S, Rodriguez J, Sanchez G, Solari A. (2006). Variation in Trypanosoma cruzi clonal composition detected in blood patients and xenodiagnosis triatomines: implications in the molecular epidemiology of Chile. Am J Trop Med Hyg 74: 1006-1012.

[11] Deane M P, Sousa MA, Pereira NM, Gonçalves AM, Momen H, Morel CM. (1984). Trypanosoma cruzi: inoculation schedules and re-isolation methods select individual strains from doubly infected mice, as demonstrated by schizodeme and zymodeme analyses. $\mathbf{J}$ Protozool 31(2): 276-80.

[12] de Luca D'oro G M, Gardenal C N, Perret B, Crisci J V, Montamat. E E (1993). Genetic structure of Trypanosoma cruzi populations from Argentina estimated from enzyme polymorphism. Parasitology 107: 405-10.

[13] Diez C, Lorenz V, Ortiz S, Gonzalez V, Racca A, Bontempi I, Manattini S, Solari A, Marcipar I. (2010). Genotyping of Trypanosoma cruzi sublineage in human samples from a North-East Argentina area by hybridization with DNA probes and specific polymerase chain reaction (PCR). Am J Trop Med Hyg 82(1): 67-73.

[14] Diosque P, Barnabé C, Padilla A M, Marco JD, Cardozo RM, Cimino RO, Nasser J R, Tibayrenc M, Basombrío M A. (2003). Multilocus enzyme electrophoresis analysis of Trypanosoma cruzi isolates from a geographically restricted endemic area for Chagas' disease in Argentina Int J Parasitol 33(10): 997-1003.

[15] González J, Muñoz S, Ortiz S, Anacona D, Salgado S, Galleguillos M, Neira I, Sagua H, Solari A. (1995). Biochemical, Inmunological, and Biological Characterization of Trypanosoma cruzi Populations of the Andean North of Chile. Exp Parasitol 81: $125-135$.

[16] Gürtler RE, Cécere MC, Petersen RM, Rubel DN, Schweigmann NJ. (1993). Chagas disease in north-west Argentina: association between Trypanosoma cruzi parasitaemia in dogs and cats and infection rates in domestic Triatoma infestans. Trans R Soc Trop Med Hyg 87:12-15

[17] Gürtler RE, Cohen JE, Cecere MC , Chuit R. (1997) Shifting host choices of the vector of Chagas disease Triatoma infestans in relation to the availability of hosts in houses in north-west Argentina. J Appl Ecol 34: 699-715

[18] Gürtler RE, Canale DM, Spillmann C, Stariolo R, Salomón OD, Blanco S, Segura EL. (2004) Effectiveness of residual spraying with deltamethrin and permethrin on peridomestic populations of Triatoma infestans in rural western Argentina: a district-wide randomized trial. Bull World Health Organ 82:196-205.

[19] Jercic M I, González C, Oyarce A, Cancino B, Mac-Lean M. (2011). La enfermedad de Chagas en Chile: componente vectorial y serología en menores de 5 años durante el período 2005-2010 Boletín de Vigilancia en Salud Pública, Instituto de Salud Pública de Chile.

[20] Lent H, Wigodzinsky P. (1979) Revision of the Triatominae (Hemiptera, Reduviidae) and their significance as vector of Chagas' disease. Bull Am Mus Nat Hist 163:123-520.

[21] López A, Crocco L, Morales G, Catalá S. Feeding frequency, infectivity and physiological status of peridomestic populations of Triatoma infestans. Acta Trop 1999; 73: 275-281.

[22] Lorca M, Garcia A, Contreras M, Schenone H, Rojas A. (2001). Evaluation of a Triatoma infestans elimination program by the decrease of Trypanosoma cruzi infection frequency in children younger than 10 years, Chile, 1991-1998, Am J Trop Med Hyg 65(6): 861-864.

[23] Macina R A, Arauzo S, Reyes M B, Sanchez D O, Solari A, Frasch CA. (1987). Trypanosoma cruzi isolates from Argentina and Chile grouped with the aid of DNA. Mol Biochem Parasitol 21: 25-32.

[24] Miles MA, Apt W, Widmer G, Povoa M M, Schofield C J. (1984). Isozyme heterogeneity and numerical taxonomy of Trypanosoma cruzi stocks from Chile. Trans R Soc Trop Med Hyg 78(4): 526-35.

[25] Miles M A, Cibulskis R E. (1986). Zymodeme characterization of Trypanosoma cruzi. Parasitol Today 2(4): 94-7.

[26] Moncayo A. 2003. Chagas disease: current epidemiological trends after the interruption of vectorial and transfusional transmission in the Southern cone countries. Mem. Inst. Oswaldo Cruz. 98: 577-591.

[27] Organización Panamericana de la Salud, 1996. Iniciativa del Cono Sur. V. Reunión de la Comisión Intergubernamental para la eliminación del Triatoma infestans y la interrupción de la Trypanosomiasis americana transfusional. OPS/HCP/HCT 96067. Organización Panamericana de la Salud. Porto Alegre, Brasil.

[28] Prata A. 2001. Clinical and epidemiological aspects of Chagas disease. Lancet Infect Dis 1: 3.

[29] Rozas, M, Botto-Mahan C, Coronado X, Ortiz S, Cattan PE, Solari A. (2005). Short report: Trypanosoma cruzi infection in wild mammals from a chagasic area of Chile Am J Trop Med Hyg 73(3): 517-519.

[30] Schofield CJ. (1985) Population dynamics and control of Triatoma infestans. Ann Soc Belg Med Trop 65:149-164. 
[31] Sanchez G, Wallace A, Muñoz S, Venegas J, Ortiz S, Solari A.( 1993) Characterization of Trypanosoma cruzi populations by several molecular markers supports a clonal mode of reproduction. Biol Res 26(1-2):167-76

[32] Torres JP, Ortiz S, Muñoz S, Solari A.(2004). Trypanosoma cruzi isolates from Chile are heterogeneous and composed of mixed populations when characterized by schizodeme and Southern analyses. Parasitology. 128: 161-168.

[33] Veas F, Brenière SF, Cuny G, Brengues C, Solari A, Tibayrenc M. (1991). General procedure to construct highly specific kDNA probes for clones of Trypanosoma cruzi for sensitive detection by polymerase chain reaction. Cell Mol Biol 37: 73-84.

[34] Wallace A, Ortíz S, Sánchez G, Villagra R, Muga M, Solari A. (2001) Studies on parasitemia courses and mortality in mice infected with genetically distant Trypanosoma cruzi clonets. Biol Res 34(2):83-90.

[35] Wincker P, Britto C, Pereira JB, Cardoso MA, Oelemann W, Morel CM. (1994). Use of a simplified polymerase chain reaction procedure to detect Trypanosoma cruzi in blood samples from chronic chagasic patients in a rural endemic area. Am J Trop Med Hyg 51: 771-777.

[36] Zeledón, R. (1983) Vectores de la enfermedad de Chagas y sus características ecofisiológicas. Interciencia 86:348-395.

[37] Zingales, B., Miles M, Campbell D, Tibayrenc M, Macedo A, Teixeira M, Schijman A, Llewellyn M, Lages-Silva E, Machado C, Andrade S, Sturm N. (2012). The revised Trypanosoma cruzi subspecific nomenclature: Rationale, epidemiological relevance and research applications. Infection, Genet and Evol 12(2): 240-253. 